\title{
CEASE: A guide for clinicians on how to stop resuscitation efforts
}
Alexia M. Torke, MS, $\mathrm{MS}^{1-4}$
Patricia Bledsoe, MSW ${ }^{1}$
Lucia D. Wocial, $\mathrm{RN}, \mathrm{PhD}^{1,4}$
Gabriel T. Bosslet, MD, MA ${ }^{1 ; 3}$
Paul R. Helft, $\mathrm{MD}^{1,3,5}$

${ }^{1}$ Charles Warren Fairbanks Center for Medical Ethics, Indiana University (IU) Health; ${ }^{2} \mathrm{IU}$

Center for Aging Research, Regenstrief Institute, Inc.; ${ }^{3} \mathrm{IU}$ Department of Medicine; ${ }^{4} \mathrm{IU}$ School

of Nursing, ${ }^{5}$ IU Melvin and Bren Simon Cancer Center; all locations in Indianapolis, Indiana

Corresponding Author/Request for Reprints:

Alexia M. Torke, MD, MS

Associate Professor of Medicine, Indiana University

HITS Building Suite 2000

410 W. 10th St.

Indianapolis, IN 46202

$317-274-9221$

atorke@iu.edu

Financial disclosures: This work was supported by the Charles Warren Fairbanks Center for Medical Ethics, which is funded by the Richard M. Fairbanks Foundation and the Methodist Health Foundation, all located in Indianapolis, Indiana

Running Head: How to stop resuscitation

Word Count: 2111 words

MeSH key words: resuscitation, physician patient relations, decision making

This is the author's manuscript of the article published in final edited form as:

Torke, A. M., Bledsoe, P., Wocial, L. D., Bosslet, G. T., \& Helft, P. R. (2015). CEASE: A Guide for Clinicians on How to Stop Resuscitation Efforts. Annals of the American Thoracic Society, 12(3), 440-445.

http://dx.doi.org/10.1513/AnnalsATS.201412-552PS 


\begin{abstract}
:
Resuscitation programs such as Advanced Cardiac Life Support, Cardiac Life Support, Pediatric Advanced Life Support and the Neonatal Resuscitation Program offer inadequate guidance to physicians who must ultimately decide when to stop resuscitation efforts. These decisions involve clinical and ethical judgments and are complicated by communication challenges, group dynamics, and family considerations. This article presents a framework, summarized in a mnemonic (CEASE: Clinical Features, Effectiveness, Ask, Stop, Explain), for how to stop resuscitation efforts and communicate that decision to clinicians and ultimately the patient's family. Rather than a decision rule, this mnemonic represents a framework based on best evidence for when physicians are considering stopping resuscitation efforts and provides guidance on how to communicate that decision.
\end{abstract}


By the end of intern year, every physician-in-training knows how to initiate a resuscitation for cardiopulmonary arrest (a "code”), but few learn how to stop it. Detailed guidelines for initiating resuscitation to adults, children and neonates are taught through the Advanced Clinical Life Support (ACLS), ${ }^{1,2}$ Pediatric Advanced Life Support (PALS) ${ }^{2,3}$ and Neonatal Resuscitation Program (NRP) $)^{4}$ programs as well as European guidelines. ${ }^{5}$ However, deciding when resuscitation efforts should be stopped is an equally difficult decision that is mostly left to individual physicians, with almost no specific instruction from experts or adequate algorithms to assist in decision making. Since the 1970s there have been efforts to empirically define clinical features that predict a low likelihood of survival from resuscitation and to develop clinical prediction rules for when to stop. These are not in widespread use, possibly due to factors such as the poor quality of empirical evidence, ${ }^{6}$ the risk of stopping resuscitation prematurely for some patients, and a medical culture that resists death at all costs. Additionally, the few prediction rules that exist for in-hospital cardiac arrest have not been updated for the latest versions of ACLS or PALS. For this reason, published resuscitation guidelines provide only general statements regarding when and how to stop resuscitation efforts (Tables 1,2).

The lack of guidelines for stopping resuscitation has left a void. Stopping a code takes place in a complex, often chaotic clinical setting. Additionally, much like a decision to write a do not resuscitate (DNR) order, stopping resuscitation is a clinical judgment based on both subjective and objective information. ${ }^{7}$ In the absence of identified uniform clinical rules for stopping resuscitation, clinicians need an easily remembered framework for how to discontinue resuscitation efforts and effectively communicate with other clinicians and family. This kind of decision entails both ethical and communication elements, all of which must be considered in the heat of the moment. 
The decision to discontinue resuscitation requires considerable clinical competence and judgment. Clinicians must address key ethical and communication factors but make decisions in a time pressured situation that is not conducive to pondering these questions in the moment. ${ }^{7}$ We believe a framework to help clinicians organize their thinking and consider several key factors would be of great use in the clinical setting. To help clinicians with these difficult tasks, we propose the brief mnemonic, CEASE. Below we outline each element of the CEASE approach and base our recommendations on clinical evidence and ethical principles.

The communication strategies we include as part of our approach should be just one step in a longer process of addressing goals of care and advance care planning. Good communication about code status before cardiopulmonary arrest may avoid unwanted or nonbeneficial resuscitative efforts. Clinician guidance for these discussions has been previously published. ${ }^{8-10}$

\section{CLINICAL FEATURES that predict survival}

There is a growing body of evidence that clinical characteristics of the patient predict survival and neurologic outcomes from resuscitation. While prediction models are imperfect at predicting outcomes for any individual patient, key clinical factors should be taken into consideration when determining the duration of resuscitation. Key pre-arrest factors associated with poor outcomes for adults include: pneumonia, metastatic cancer, hypotension, renal failure, and poor functional status (Table 3). ${ }^{11,12}$ Ebell et al developed a prediction model for neurologic outcome and found that good neurologic function on hospital admission is most highly associated with a good neurologic outcome after resuscitation (able to work with minimal impairment), while trauma, stroke and age 85 or older are associated with greater impairment. ${ }^{13}$ In children, renal failure and epinephrine infusion prior to the arrest were associated with 
mortality. ${ }^{14}$ Therefore knowing the patient’s history is critical. In some situations, physicians perform resuscitation on a patient they know well and are aware of these clinical factors already. Unfortunately, given the complexity of the modern hospital, many resuscitation efforts are performed by physicians who are unaware of the patient's history. Providing the team leader with quick, accurate information about the patient's clinical history is critical to good decision making. For purposes of acutely refining the patient's immediate prognosis members of the team should work together to quickly access clinical information and provide it to the code team, especially the clinician who is in charge of resuscitation efforts,

\section{EFFECTIVENESS of resuscitation efforts}

The quality of resuscitation interventions is associated with arrest outcome. ${ }^{15-17}$ Clinicians must carefully adhere to CPR quality metrics: adequate compression rate, adequate compression depth, full chest recoil after each compression, minimizing pauses in compressions and avoiding excessive ventilation (Table 3). ${ }^{18}$ It is the entire sequence of actions (flow) rather than single events that determine the success of the intervention. ${ }^{6}$

Other clinical features of the pre-arrest period have also been shown to be predictive of outcomes. Initial rhythm of ventricular fibrillation or pulseless ventricular tachycardia is associated with better outcomes than asystole or pulseless electrical activity. ${ }^{19}$ One decision aid found a negative predictive value of $98.9 \%$ for being discharged alive if the patient did not have any of the following: an initial rhythm of ventricular fibrillation or ventricular tachycardia or return of a pulse within 10 minutes of chest compressions. ${ }^{20}$ Some researchers have found that few patients survive prolonged resuscitation efforts, ${ }^{11}$ with a steep decline in survival for increased resuscitation time. ${ }^{21,22}$ However, more recent evidence suggests that children with 
cardiac conditions have a higher (>20\%) rate of survival with resuscitation over 35 minutes. ${ }^{22}$ Indirect evidence for longer efforts in adults comes from a large patient registry, which found that hospitals with longer resuscitation times have better overall survival. ${ }^{23}$ It is hard to determine if this finding is due to the duration of resuscitation or to other factors such as the cause of the cardiac arrest.

Given these complex and sometimes contradictory data, there is no specific clinical decision aid that is widely accepted as a guide to stop in-hospital resuscitation efforts or that has ever been included in resuscitation guidelines for in-hospital use. Clinicians are left with the difficult task of weighing key clinical factors to determine when resuscitation has such a low likelihood of success that it should be stopped.. Clearly the length of the resuscitative efforts and the patient's physiological response in real time are key clinical factors and should be considered when evaluating whether or not to continue resuscitation efforts.

\section{ASK the other clinicians present for input}

ACLS guidelines now focus on the importance of good communication and teamwork among the resuscitation team. One aspect of communication is knowledge sharing. ${ }^{1}$ It is essential for the team leader to have input from other clinicians at the bedside who can contribute to decision making. Other members of the interdisciplinary team may have relevant knowledge about the patient's clinical history or current clinical condition. Examples may include a nurses’ concern about a recent potassium value of which the physician is unaware or a respiratory therapist's observation that there is considerable resistance with bag-valve-mask ventilation. Additionally, patients or their surrogates may have revealed key information to clinicians about values and preferences that would support a focus on quality of life rather than quantity of life. 
Other participating clinicians may be able to suggest potentially useful interventions overlooked in the heat of the moment by the team leader.

In the hierarchical environment of the hospital, it may be hard for trainees or nonphysicians to speak up; research from both aviation ${ }^{1}$ and medicine ${ }^{24}$ have demonstrated the importance of a non-hierarchical approach to offering information to providing safe, effective, beneficial patient care. It is essential that the team leader be proactive about asking for input from other team members. It is up to the clinician running the code to make a decision about which suggestions require immediate action.

\section{STOP resuscitation efforts}

If resuscitation efforts are unsuccessful in achieving return of spontaneous circulation or the interventions needed to support circulation are unsustainable, it is the responsibility of the clinician running the resuscitation to decide when to stop further efforts. ${ }^{25,26}$ Although this may seem intuitively obvious, ceasing resuscitation is an emotionally and cognitively difficult task. More than any other event, this places the physician in the position of determining the timing of the patient's death. This may be part of the reason why many codes continue well beyond the duration that they are likely to be effective.

There are several factors that may contribute to the difficulty of stopping resuscitation efforts. First, once advance treatment interventions are started, there is tremendous momentum to continue them. This "technologic imperative"27 may lead to continued treatment when it is no longer of benefit. Second, efforts to improve hospital quality have included general and disease

specific in-hospital mortality as quality indicators. ${ }^{28-30}$ The pressure to reduce hospital mortality may place tacit pressure on team members to continue resuscitation. Finally, these important life 
or death decisions are frequently made under pressure of time and emotion, about patients unfamiliar to the treating clinicians.

Mounting evidence supports a change in practice from escorting family out of the room to allowing them to witness resuscitative efforts. ${ }^{2,26,31-33}$ Family presence has the advantage of allowing family members to witness the aggressive care provided to the patient, permits them to be present at the time of death, and may have lasting positive psychological benefits. ${ }^{34,35}$ There are guidelines to help support families during the process and to debrief afterwards. ${ }^{26,33}$ However, there is evidence that clinicians vary in their support of family presence. ${ }^{36}$ The presence of family may make stopping the resuscitation efforts more challenging, particularly if the family has been strongly in favor of continued aggressive care.

We cannot overemphasize that it is not acceptable to ask the family whether or not resuscitation efforts should continue or stop, ${ }^{26}$ a strategy that several of us have witnessed in our clinical practices. While surrogates play a key role in the decision making process related to goals of care and treatment decisions such as code status, ${ }^{37}$ stopping resuscitation efforts is a decision that should be based on the patient's clinical status and the likely success of ongoing resuscitation efforts (as discussed above), and therefore is not within the purview of family members. Additionally, asking a family member whether to stop resuscitation puts the burden of determining the time of death on the shoulders of the patient's loved one. For both of these reasons, asking a family member whether resuscitation should be discontinued is ethically unacceptable. 


\section{EXPLAIN what has happened to the family}

When resuscitation efforts cease, the clinical team has important obligations to the family: inform them about what has occurred, answer questions, and provide emotional support. ${ }^{38}$ In many cases, physicians will be assisted in these tasks by nurses, social workers, or chaplains. Evidence has shown that family members of critically ill adults and children are at high risk for posttraumatic stress, anxiety and depression and that this risk is especially high if the patient dies..$^{39,40}$ Compassionate disclosure about the events of the resuscitation, including the death of the patient if this has occurred, is an essential part of medical practice and can be taught successfully. ${ }^{41,42}$ Core skills include showing empathy and responding to family emotion. ${ }^{43,44}$

The discussion will vary considerably depending on whether the patient survived and whether the family has witnessed the resuscitation. For family members who were present, the act of witnessing resuscitation may require immediate emotional support and attention from a member of the team who was not directly involved in the resuscitation efforts. For family members who were not present, clinicians need to inform them about the death in a compassionate manner, avoiding medical jargon and providing emotional support. Trainees may be helped by expert guidance for how to inform families about bad news, such as the SPIKES protocol $^{45}$ and may benefit from training that includes role play and other active learning strategies. $^{46,47}$

\section{Discussion}

In the absence of a DNR order, the decision to start resuscitation is automatic and rests frequently with nurses who are the providers most likely to be present when a patient has a cardiopulmonary arrest. However, the decision to continue or terminate resuscitative efforts 
rests with the clinician leading resuscitation efforts, usually a physician. The lack of clinical prediction rules means that clinicians involved in the code must use the available information about the patient's premorbid condition, current acute illness, and the trajectory of the resuscitation to determine when to discontinue efforts. This lack of clear guidelines requires that clinicians make the judgment to stop resuscitation efforts in a situation of uncertainty.

We propose the CEASE framework as a helpful framework for physicians and other clinicians who are learning resuscitation skills. Instead of providing a decision rule for stopping resuscitation based on clinical factors, we have outlined a process for considering when to discontinue resuscitative efforts and how to effectively communicate with clinicians and family. It is meant to complement existing ACLS, PALS, CLS and NRP guidelines to provide care that is clinically sound, respectful of the patient, family, and the clinical team, and flows from ethically sound principles. We emphasize that the clinician directing the resuscitation must decide when to stop efforts and cannot look to family members to make this decision. Finally, our obligation to family involves providing information and support during their time of loss. 
Table 1. Adult guidelines for stopping cardiopulmonary resuscitation

\begin{tabular}{|c|c|c|c|}
\hline Resource & Clinical Factors & Arrest-related factors & Decision Making \\
\hline $\begin{array}{l}\text { European } \\
\text { Resuscitation Council } \\
\text { Guidelines for } \\
\text { Resuscitation: } \\
\text { Ethics }^{25}\end{array}$ & $\begin{array}{l}\text { "medical history and } \\
\text { anticipated prognosis, } \\
\text { the period between } \\
\text { cardiac arrest and start } \\
\text { of CPR, the interval to } \\
\text { defibrillation and the } \\
\text { period of advanced } \\
\text { life support (ALS) } \\
\text { with continuing } \\
\text { asystole and no } \\
\text { reversible cause." }\end{array}$ & $\begin{array}{l}\text { Continue as long as } \\
\text { VF persists } \\
\text { Acceptable to stop } \\
\text { after asystole of } 20 \\
\text { minutes or more }\end{array}$ & $\begin{array}{l}\text { Decision should be } \\
\text { "made by the team } \\
\text { leader, but after } \\
\text { consultation with } \\
\text { other team members, } \\
\text { who may have valid } \\
\text { points to contribute." } \\
\text { "...the decision is } \\
\text { based on the clinical } \\
\text { judgement that the } \\
\text { patient's arrest is } \\
\text { unresponsive to ALS" }\end{array}$ \\
\hline $\begin{array}{l}\text { American Heart } \\
\text { Association } \\
\text { Guidelines: Ethics }{ }^{38}\end{array}$ & $\begin{array}{l}\text { Witnessed arrest } \\
\text { Time to CPR } \\
\text { Initial rhythm } \\
\text { Time to defibrillation } \\
\text { Comorbid disease } \\
\text { Prearrest state } \\
\text { ROSC* during } \\
\text { resuscitative efforts }\end{array}$ & $\begin{array}{l}\text { The evidence for } \\
\text { clinical decision rules } \\
\text { for adults is limited. }\end{array}$ & $\begin{array}{l}\text { For adults: the } \\
\text { decision to stop rests } \\
\text { with the treating } \\
\text { physician. }\end{array}$ \\
\hline $\begin{array}{l}\text { American Heart } \\
\text { Association Advanced } \\
\text { Cardiac Life Support } \\
\text { Provider Manual }^{1}\end{array}$ & Not addressed & Not addressed & Not addressed \\
\hline
\end{tabular}

*ROSC: Return of Spontaneous Circulation 
Table 2. Pediatric

\begin{tabular}{|c|c|c|c|}
\hline Resource & Clinical Factors & Arrest-related factors & Decision Making \\
\hline $\begin{array}{l}\text { European } \\
\text { Resuscitation } \\
\text { Guidelines for } \\
\text { Resuscitation: } \\
\text { Paediatrics }\end{array}$ & $\begin{array}{l}\text { Newborns: } \\
\text { Where gestation, birth } \\
\text { weight and/or } \\
\text { congenital anomalies } \\
\text { are associated with } \\
\text { almost certain early } \\
\text { death, and } \\
\text { unacceptably high } \\
\text { morbidity is likely } \\
\text { among the rare } \\
\text { survivors, } \\
\text { resuscitation is not } \\
\text { indicated. }\end{array}$ & $\begin{array}{l}\text { Newborns: } \\
\text { "After } 10 \text { min of } \\
\text { continuous and } \\
\text { adequate resuscitation } \\
\text { efforts, } \\
\text { discontinuation of } \\
\text { resuscitation may be } \\
\text { justified if there are } \\
\text { no signs of life." }\end{array}$ & Not addressed? \\
\hline $\begin{array}{l}\text { American Heart } \\
\text { Association } \\
\text { Guidelines: Ethics }^{38}\end{array}$ & $\begin{array}{l}\text { Newborns: } \\
\text { Resuscitation is not } \\
\text { indicated for } \\
\text { newborns with } \\
\text { "almost certain early } \\
\text { death and when } \\
\text { unacceptably high } \\
\text { mortality is likely } \\
\text { among the rare } \\
\text { survivors. } \\
\text { Children: } \\
\text { Duration of CPR } \\
\text { Witnessed event } \\
\text { Number of doses of } \\
\text { epinephrine } \\
\text { Etiology of arrest } \\
\text { Rhythm } \\
\text { Age }\end{array}$ & $\begin{array}{l}\text { In a newborn with no } \\
\text { detectable heart rate, } \\
\text { "it is appropriate to } \\
\text { consider stopping } \\
\text { resuscitation if the } \\
\text { heart rate remains } \\
\text { undetectable for } 10 \\
\text { minutes." } \\
\text { There are no validated } \\
\text { clinical rules for } \\
\text { children. }\end{array}$ & $\begin{array}{l}\text { For children: } \\
\text { "In the absence of } \\
\text { clinical decision rules, } \\
\text { the responsible } \\
\text { clinician should stop } \\
\text { the resuscitative } \\
\text { attempt if there is a } \\
\text { high degree of } \\
\text { certainty that the } \\
\text { patient will not } \\
\text { respond to further } \\
\text { pediatric life support." }\end{array}$ \\
\hline $\begin{array}{l}\text { American Heart } \\
\text { Association Pediatric } \\
\text { Provider Manual }^{3}\end{array}$ & $\begin{array}{l}\text { interval from collapse } \\
\text { to initiation of CPR; } \\
\text { quality of CPR; } \\
\text { duration of } \\
\text { resuscitation; } \\
\text { underlying conditions. } \\
\text { Consider prolonged } \\
\text { efforts in: }\end{array}$ & Not addressed & Not addressed \\
\hline
\end{tabular}




\begin{tabular}{|c|c|c|c|}
\hline & $\begin{array}{l}\text { Recurring or } \\
\text { refractory VF/VT } \\
\text { Drug toxicity } \\
\text { Hypothermia }\end{array}$ & & \\
\hline $\begin{array}{l}\text { Neonatal } \\
\text { Resuscitation } \\
\text { Program } \\
\text { Textbook }\end{array}$ & $\begin{array}{l}\text { Considerations for } \\
\text { noninitition of } \\
\text { resuscitation: } \\
\text { - } \quad \text { Confirmed } \\
\text { gestational age of } \\
\text { less than } 23 \text { weeks } \\
\text { or birth weight } \\
\text { under } 400 \mathrm{~g} \\
\text { - Anencephaly } \\
\text { - Confirmed lethal } \\
\text { genetic disorder or } \\
\text { malformation } \\
\text { - When available } \\
\text { data suggests an } \\
\text { unacceptably high } \\
\text { likelihood of } \\
\text { death/severe } \\
\text { disability }\end{array}$ & $\begin{array}{l}\text { "If you can confirm } \\
\text { that no heart rate has } \\
\text { been detectable for at } \\
\text { least } 10 \text { minutes, } \\
\text { discontinuation of } \\
\text { resuscitation may be } \\
\text { appropriate." }\end{array}$ & $\begin{array}{l}\text { Promote shared } \\
\text { decision making with } \\
\text { parents prior to } \\
\text { delivery when } \\
\text { noninitiation is } \\
\text { considered. }\end{array}$ \\
\hline
\end{tabular}


Table 3: Potential factors in adult in-hospital resuscitation outcome

\begin{tabular}{|c|c|c|}
\hline \multirow[t]{2}{*}{ Pre-Arrest Clinical Factors } & \multicolumn{2}{|l|}{ During Arrest } \\
\hline & Arrest Factors & Resuscitation efforts \\
\hline 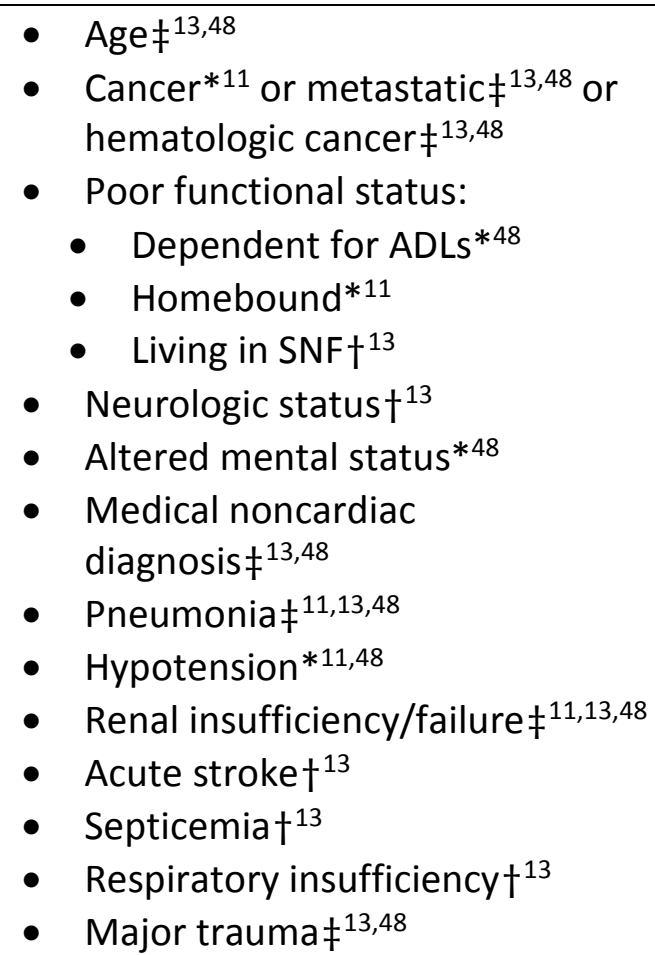 & $\begin{array}{l}\text { - Witnessed arrest*49 } \\
\text { - Initial rhythm, } \\
\text { ventricular fibrillation, } \\
\text { pulseless ventricular } \\
\text { tachycardia*49 } \\
\text { - } \text { Return of pulse within } \\
10 \text { minutes of chest } \\
\text { compressions } * 49 \\
\text { - Duration of arrest }{ }^{11 *} \\
\text { (conflicting data about } \\
\text { direction of effect) }\end{array}$ & 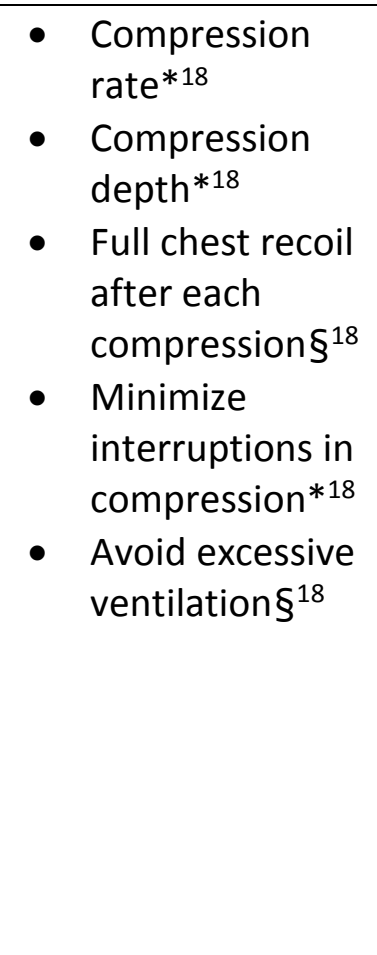 \\
\hline
\end{tabular}

*Associated with survival †Associated with neurological outcome $\ddagger$ Associated with both survival and neurological outcome $\S$ Based on expert opinion, or data from laboratory or out of hospital arrest studies 


\section{References}

1. American Heart Association. Advanced Cardiovascular Life Support Provider Manual. American Heart Association; 2011.

2. Field JM, Hazinski MF, Sayre MR, et al. Part 1: executive summary: 2010 American Heart Association Guidelines for Cardiopulmonary Resuscitation and Emergency Cardiovascular Care. Circulation. Nov 2 2010;122(18 Suppl 3):S640-656.

3. American Heart Association. Pediatric Advanced Life Support (PALS) Provider Manual. American Heart Association; 2011.

4. Kattwinkel J, McGowan, J. E., Zaichkin J. Textbook of Neonatal Resuscitation. 6th Ed. ed: American Academy of Pediatrics 2011.

5. Nolan JP, Deakin CD, Soar J, Bottiger BW, Smith G. European Resuscitation Council Guidelines for Resuscitation 2005: Section 4. Adult advanced life support. Resuscitation.67:S39-S86.

6. Mancini ME, Soar J, Bhanji F, et al. Part 12: Education, implementation, and teams: 2010 International Consensus on Cardiopulmonary Resuscitation and Emergency Cardiovascular Care Science With Treatment Recommendations. Circulation. Oct 19 2010;122(16 Suppl 2):S539-581.

7. Ranola PA, Merchant RM, Perman SM, et al. How long is long enough, and have we done everything we should?-Ethics of calling codes. Journal of medical ethics. Sep 232014.

8. Chittenden EH, Clark ST, Pantilat SZ. Discussing resuscitation preferences with patients: challenges and rewards. J Hosp Med. Jul 2006;1(4):231-240.

9. Szmuilowicz E, Neely KJ, Sharma RK, Cohen ER, McGaghie WC, Wayne DB. Improving residents' code status discussion skills: a randomized trial. J Palliat Med. Jul 2012;15(7):768-774.

10. Chittenden EH, Anderson WG, Lai CJ, O'Sullivan P. An evaluation of interactive web-based curricula for teaching code status discussions. J Palliat Med. Sep 2013;16(9):1070-1073.

11. Bedell SE, Delbanco TL, Cook EF, Epstein FH. Survival after cardiopulmonary resuscitation in the hospital. N Engl J Med. Sep 8 1983;309(10):569-576.

12. Ebell MH, Preston PS. The effect of the APACHE II score and selected clinical variables on survival following cardiopulmonary resuscitation. Family medicine. Mar 1993;25(3):191-196.

13. Ebell MH, Jang W, Shen Y, Geocadin RG, Get With the Guidelines-Resuscitation I. Development and validation of the Good Outcome Following Attempted Resuscitation (GO-FAR) score to predict neurologically intact survival after in-hospital cardiopulmonary resuscitation. JAMA Intern Med. Nov 11 2013;173(20):1872-1878.

14. de Mos N, van Litsenburg RLL, McCrindle B, Bohn DJ, Parshuram CS. Pediatric in-intensive-careunit cardiac arrest: Incidence, survival and predictive factors. Critical care medicine. 2006;34:1209-1215.

15. Gallagher EJ, Lombardi G, Gennis P. Effectiveness of bystander cardiopulmonary resuscitation and survival following out-of-hospital cardiac arrest. Jama. Dec 27 1995;274(24):1922-1925.

16. Berg RA, Sanders AB, Kern KB, et al. Adverse hemodynamic effects of interrupting chest compressions for rescue breathing during cardiopulmonary resuscitation for ventricular fibrillation cardiac arrest. Circulation. Nov 13 2001;104(20):2465-2470.

17. Vadeboncoeur T, Stolz U, Panchal A, et al. Chest compression depth and survival in out-ofhospital cardiac arrest. Resuscitation. Feb 2014;85(2):182-188.

18. Meaney PA, Bobrow BJ, Mancini ME, et al. Cardiopulmonary resuscitation quality: [corrected] improving cardiac resuscitation outcomes both inside and outside the hospital: a consensus statement from the American Heart Association. Circulation. Jul 23 2013;128(4):417-435.

19. Marwick TH, Case CC, Siskind V, Woodhouse SP. Prediction of survival from resuscitation: a prognostic index derived from multivariate logistic model analysis. Resuscitation. Oct 1991;22(2):129-137. 
20. van Walraven C, Forster AJ, Parish DC, et al. Validation of a clinical decision aid to discontinue inhospital cardiac arrest resuscitations. Jama. Mar 28 2001;285(12):1602-1606.

21. Ballew KA, Philbrick JT, Caven DE, Schorling JB. Predictors of survival following in-hospital cardiopulmonary resuscitation. A moving target. Arch Intern Med. Nov 14 1994;154(21):24262432.

22. Matos RI, Watson RS, Nadkarni VM, et al. Duration of cardiopulmonary resuscitation and illness category impact survival and neurologic outcomes for in-hospital pediatric cardiac arrests. Circulation. Jan 29 2013;127(4):442-451.

23. Goldberger ZD, Chan PS, Berg RA, et al. Duration of resuscitation efforts and survival after inhospital cardiac arrest: an observational study. Lancet. Oct 27 2012;380(9852):1473-1481.

24. Clancy CM, Tornberg DN. TeamSTEPPS: assuring optimal teamwork in clinical settings. American journal of medical quality : the official journal of the American College of Medical Quality. MayJun 2007;22(3):214-217.

25. Baskett PJ, Steen PA, Bossaert L, European Resuscitation C. European Resuscitation Council guidelines for resuscitation 2005. Section 8 . The ethics of resuscitation and end-of-life decisions. Resuscitation. Dec 2005;67 Suppl 1:S171-180.

26. Biarent $D$, Bingham R, Richmond $S$, et al. European Resuscitation Council guidelines for resuscitation 2005. Section 6. Paediatric life support. Resuscitation. Dec 2005;67 Suppl 1:S97133.

27. Barger-Lux MJ, Heaney RP. For better and worse: the technological imperative in health care. Social science \& medicine. 1986;22(12):1313-1320.

28. Improvement IfH. Move Your Dot ${ }^{\mathrm{TM}}$ : Measuring, Evaluating, and Reducing Hospital Mortality Rates (Part 1). IHI Innovation Series white paper. . 2003; www.IHI.org. Accessed October 26, 2014.

29. Lilfort R, Provanost P. Using hospital mortality rates to judge hospital performance: a bad idea that just won't go away. BMJ. 2010;340:c2016.

30. AHRQ issues critical analysis of patient safety practices. The Quality letter for healthcare leaders. Aug 2001;13(8):8-12, 11.

31. Critchell CD, Marik PE. Should family members be present during cardiopulmonary resuscitation? A review of the literature. The American journal of hospice \& palliative care. AugSep 2007;24(4):311-317.

32. Dalio AM. Family presence during cardiopulmonary resuscitation. American journal of critical care : an official publication, American Association of Critical-Care Nurses. Jul 2008;17(4):310; author reply 310-311.

33. Lippert FK, Raffay V, Georgiou M, Steen PA, Bossaert L. European Resuscitation Council Guidelines for Resuscitation 2010 Section 10. The ethics of resuscitation and end-of-life decisions. Resuscitation. Oct 2010;81(10):1445-1451.

34. Jabre $\mathrm{P}$, Belpomme $\mathrm{V}$, Azoulay $\mathrm{E}$, et al. Family presence during cardiopulmonary resuscitation. The New England journal of medicine. Mar 14 2013;368(11):1008-1018.

35. Jabre $\mathrm{P}$, Tazarourte $\mathrm{K}$, Azoulay $\mathrm{E}$, et al. Offering the opportunity for family to be present during cardiopulmonary resuscitation: 1-year assessment. Intensive care medicine. Jul 2014;40(7):981987.

36. Sacchetti A, Carraccio C, Leva E, Harris RH, Lichenstein R. Acceptance of family member presence during pediatric resuscitations in the emergency department: effects of personal experience. Pediatric emergency care. Apr 2000;16(2):85-87.

37. Buchanan, Brock. Deciding for others: The ethics of surrogate decision making. Cambridge: Cambridge University Press; 1990. 
38. Morrison LJ, Kierzek G, Diekema DS, et al. Part 3: ethics: 2010 American Heart Association Guidelines for Cardiopulmonary Resuscitation and Emergency Cardiovascular Care. Circulation. Nov 2 2010;122(18 Suppl 3):S665-675.

39. Azoulay E, Pochard F, Kentish-Barnes N, et al. Risk of post-traumatic stress symptoms in family members of intensive care unit patients. Am J Respir Crit Care Med. May 1 2005;171(9):987-994.

40. Davidson JE, Jones C, Bienvenu OJ. Family response to critical illness: Postintensive care syndrome-family. Crit Care Med. 2012;40:618-624.

41. Hobgood CD, Tamayo-Sarver JH, Hollar DW, Sawning S. Griev_Ing: death notification skills and applications for fourth-year medical students. Teaching and Learning in Medicine. 2009;21:207219.

42. Shoenberger JM, Yeghiazarian S, Rios C, Henderson SO. Death notification in the emergency department: Survivors and physicians. Western Journal of Emergency Sedicine. 2013;14:181-185.

43. Back AL, Arnold RM, Baile WF, et al. Efficacy of communication skills training for giving bad news and discussing transitions to palliative care. Arch Intern Med. Mar 12 2007;167(5):453-460.

44. Vitaltalk. http://www.vitaltalk.org/. Accessed January 29, 2015.

45. Baile WF, Buckman R, Lenzi R, Glober G, Beale EA, Kudelka AP. SPIKES-A six-step protocol for delivering bad news: application to the patient with cancer. The oncologist. 2000;5(4):302-311.

46. Garg A, Buckman R, Kason Y. Teaching medical students how to break bad news. CMAJ : Canadian Medical Association journal = journal de l'Association medicale canadienne. Apr 15 1997;156(8):1159-1164.

47. Hobgood C, Harward D, Newton K, Davis W. The educational intervention "GRIEV_ING" improves the death notification skills of residents. Academic emergency medicine : official journal of the Society for Academic Emergency Medicine. Apr 2005;12(4):296-301.

48. Ebell MH, Afonso AM. Pre-arrest predictors of failure to survive after in-hospital cardiopulmonary resuscitation: a meta-analysis. Family Practice. 2011;28:505-515.

49. Van Walraven C FA, Parish DC et al. Validation of a clinical decision aid to discontinue in-hospital cardiac arrest resuscitations. JAMA. 2001;285:1602-1606. 